\title{
Hydrogen Silsesquioxane based silica glass coatings for the corrosion protection of austenitic stainless steel
}

\author{
Lampert, Felix; Jensen, Annemette Hindhede; Din, Rameez Ud; Møller, Per
}

Published in:

Surface and Coatings Technology

Link to article, DOI:

10.1016/j.surfcoat.2016.10.020

Publication date:

2016

Document Version

Peer reviewed version

Link back to DTU Orbit

Citation (APA):

Lampert, F., Jensen, A. H., Din, R. U., \& Møller, P. (2016). Hydrogen Silsesquioxane based silica glass coatings for the corrosion protection of austenitic stainless steel. Surface and Coatings Technology, 307(Part A), 879-885. https://doi.org/10.1016/j.surfcoat.2016.10.020

\section{General rights}

Copyright and moral rights for the publications made accessible in the public portal are retained by the authors and/or other copyright owners and it is a condition of accessing publications that users recognise and abide by the legal requirements associated with these rights.

- Users may download and print one copy of any publication from the public portal for the purpose of private study or research.

- You may not further distribute the material or use it for any profit-making activity or commercial gain

- You may freely distribute the URL identifying the publication in the public portal 
Hydrogen Silsesquioxane based silica glass coatings for the corrosion protection of austenitic stainless steel

By

Felix Lampert ${ }^{a}$, Annemette Hindhede Jensen ${ }^{b}$, Rameez Ud Din ${ }^{c}$, Per Moller ${ }^{d}$

${ }^{a}$ Technical University of Denmark (DTU),Department of Mechanical Engineering,

Produktionstorvet, Building 425, 2800 Kgs. Lyngby, Denmark, e-mail:felamp@mek.dtu.dk

${ }^{b}$ SiOx ApS, Bybjergvej 7, 3060 Espergarde, Denmark, e-mail: annemette@siox.dk

${ }^{c}$ Technical University of Denmark (DTU),Department of Mechanical Engineering,

Produktionstorvet, Building 425, 2800 Kgs. Lyngby, Denmark, e-mail: rudin@mek.dtu.dk

${ }^{d}$ Technical University of Denmark (DTU),Department of Mechanical Engineering,

Produktionstorvet, Building 425, 2800 Kgs. Lyngby, Denmark, e-mail: pm@mek.dtu.dk

Corresponding author: Felix Lampert, e-mail: felamp@mek.dtu.dk 


\begin{abstract}
The application of stainless steels in hostile environments, such as concentrated acid or hot sea water, requires additional surface treatments, considering that the native surface oxide does not guarantee sufficient corrosion protection under these conditions. In the present work, silica-like thin-film barrier coatings were deposited on AISI 316 L grade austenitic stainless steel with $2 B$ surface finish from Hydrogen Silsesquioxane (HSQ) spin-on-glass precursor and thermally cured to tailor the film properties. Results showed that curing at $500{ }^{\circ} \mathrm{C}$ resulted in a filmstructure with a polymerized siloxane backbone and a reduced amount of Si-H moieties. The coatings showed good substrate coverage and the average thickness was between 200 and 400 $\mathrm{nm}$ on the rough substrate surface, however, film thicknesses of more than $1400 \mathrm{~nm}$ were observed at substrate defects. Deposition of these films significantly improved the barrier properties by showing a 1000 times higher modulus while an ionic transport over the coating was also observed.
\end{abstract}

Keywords: Barrier Coating; Corrosion; Electrochemical Impedance Spectroscopy; Hydrogen Silsesquioxane; Thin Film 


\section{Introduction}

Stainless steels owe their resistivity against galvanic corrosion to a high $\mathrm{Cr}$ content, which triggers the formation of a thin, Cr-rich surface-oxide with a low ionic conductivity and solubility, that protects the underlying material from chemical attack in neutral and alkaline environments[1]. However, the native oxide becomes unstable at low $\mathrm{pH}$ ( $\mathrm{pH}$ below approx. 4)[2] and consequently corrosion of stainless steels can be initiated under acidic conditions. Apart from uniform breakdown of the native oxide film, stainless steels are susceptible to localized corrosion in form of pitting and crevice corrosion in chloride containing electrolytes such as sea water[3,4], and therefore the application of stainless steels in acidic or chloride containing environments may require further protection of the material.

Vitreous enamel coatings find wide industrial application as barrier coatings to increase the corrosion resistance of materials[5-7]. Traditionally, porcelain or glass coatings are applied from powdered precursors and fired at elevated temperatures, thereby fusing the solid particles and forming an envelope-type coating which acts as a corrosion barrier between substrate and corrosive medium. However, this technology is limited to rather thick, brittle coatings, which alter the optical appearance and geometry of the substrate and are prone to brittle fracture. In this regard, thin coating systems can potentially overcome the drawbacks of traditional enamels, while retaining their protective properties. It has been reported in literature[8-14], that $\mathrm{SiO}_{2}$ thin film coatings can substantially increase the aqueous as well as high temperature corrosion resistance of stainless steel substrates and high quality $\mathrm{SiO}_{2}$ thin films have been successfully deposited on stainless steel substrates by Physical Vapor Deposition (PVD)[15], Chemical Vapor Deposition (CVD)[8,9,14,16-18] and Liquid Phase Deposition (LPD)[19]. However, the cost of 
processing equipment for vapor phase processes is high, while LPD processes rely on highly hazardous precursors such as $\mathrm{H}_{2} \mathrm{SiF}_{6}$ [19].

As an economically feasible and non-hazardous alternative, $\mathrm{SiO}_{2}$ deposition on stainless steel from liquid precursors by the sol-gel method has been demonstrated[10,11,13,20]. Within common sol-gel processing, a tetrafunctional alkoxide precursor with the alkyl group R, such as tetraethyl orthosilicate (TEOS), is hydrolyzed according to reaction (1) and subsequently condensed to form siloxane bonds via alcohol or water condensation according to reactions (2),(3)[21].

$$
\begin{array}{ll}
\equiv \mathrm{SiOR}+\mathrm{H}_{2} \mathrm{O} \rightarrow \equiv \mathrm{SiOH}+\mathrm{ROH} & \text { (hydrolysis) } \\
\equiv \mathrm{SiOR}+\equiv \mathrm{SiOH} \rightarrow \equiv \mathrm{SiOSi} \equiv+\mathrm{ROH} & \text { (alcohol condensation) } \\
2 \equiv \mathrm{SiOH} \rightarrow \equiv \mathrm{SiOSi} \equiv \mathrm{H}_{2} \mathrm{O} & \text { (water condensation) }
\end{array}
$$

The main advantage of these processes is the ease of their application, i.e. deposition by high throughput processes such as spray or dip coating and curing in simple heating equipment. However, sol-gel $\mathrm{SiO}_{2}$ from aqueous solution is porous in nature and high temperature sintering is required to densify and convert porous films to continuous $\mathrm{SiO}_{2}$ films[22]. In this perspective, the aqueous corrosion properties of sol-gel coated stainless steels cured at medium temperature are under discussion: Vasconcelos et al.[10] tested sol-gel $\mathrm{SiO}_{2}$ coated stainless steel samples and observed a decrease in corrosion rate in sulfuric acid as well as an increase in pitting potential combined with a decrease in passive current in aqueous $\mathrm{NaCl}$ solution. Moreover, de Sanctis et al.[11] found an improvement in resistance to corrosion in hot nitric acid for sol-gel $\mathrm{SiO}_{2}$ coated stainless steel and Nikrooz et al.[13] demonstrated an improvement of the high temperature oxidation resistance as well as wet corrosion resistance ferritic stainless steel after 
dip coating with sol-gel silica. On the contrary, Damborenea et al.[20] reported results, which did not indicate an improvement in corrosion resistance in acid or aqueous $\mathrm{NaCl}$ solution. Recent studies by Takemori[23,24] reported a sol-gel process from non-aqueous solution to deposit nonporous $\mathrm{SiO}_{2}$ films on stainless steel substrate. However, the coatings produced by their method showed cracking and defoliation and consequently cannot be evaluated as suitable candidates for corrosion barrier coatings.

As an alternative approach to deposit $\mathrm{SiO}_{2}$ from wet precursor, thin $\mathrm{SiO}_{2}$-like films based on Hydrogen Silsesquioxane (HSQ) technology have been reported in literature[25-27]. HSQ is an oligomeric molecule with the formula $\left(\mathrm{HSiO}_{3 / 2}\right)_{\mathrm{n}}$, which, under the appropriate heat treatment, is capable of cross linking via a multi-step bond redistribution under reaction (4)[28] or dissociation of $\mathrm{Si}-\mathrm{H}$ bonds under reaction (5)[25] to form $\mathrm{SiO}_{2}$-like films[25,29].

$4 \mathrm{HSiO}_{3 / 2} \rightarrow 3 \mathrm{SiO}_{4 / 2}+\mathrm{SiH}_{4}$

$2 \mathrm{H}_{2} \mathrm{SiO}_{2 / 2} \rightarrow 2 \mathrm{H}_{2}+\mathrm{Si}_{2} \mathrm{O}_{2 / 2}$

Thereby, heat treatment at higher temperatures leads to more advanced degrees of curing and may result in the formation of films with similar properties to $\mathrm{SiO}_{2}$ deposited via CVD processes[26]. Moreover, HSQ-based thin films have gained particular interest as interlayer dielectric in microelectronics, since the thin film properties can be precisely tailored to achieve low dielectric constants[25,26,29], which can enhance the performance of integrated circuits[30]. In recent years, HSQ has come into focus as material applied on metallic substrates, due to its ability to level rough substrates[31-34], induce nano-patterns in injection molding[35] or act as corrosion barrier coating[36,37]. The material can be spin[25,38], spray[32,34] or dip[37] coated, i.e. is, similar to sol-gel coatings, capable for high-throughput processing. In the present study, HSQ spin-on-glass was investigated as a novel precursor to form thin film $\mathrm{SiO}_{2}$ coatings 
for the corrosion protection of stainless steel. Further, the microstructure, chemical composition and corrosion properties of these films were characterized in detail by using Field Emission Gun (FEG) and Focused Ion Beam (FIB) scanning electron microscopy (SEM), Fourier Transformed Infrared Spectroscopy (FT-IR), Spectroscopic Ellipsometry and Electrochemical Impedance Spectroscopy (EIS).

\section{Materials and methods}

\subsection{Coating deposition}

AISI 316L test coupons (sheet material, area of $50 \times 100 \mathrm{~mm}^{2}$, thickness $1 \mathrm{~mm}, 2 \mathrm{~B}$ surface finish) and Si wafers (thickness $675 \mu \mathrm{m}$, front side polished, backside etched) were partially dip coated with $1 \mathrm{~mm} / \mathrm{s}$ withdrawal speed in a solution of HSQ in silanol-based solvent (Dow Corning FoX25) in a single dip-cycle. Afterwards the test coupons were subjected to a heat treatment in order to form silica-like thin film coatings within $24 \mathrm{~h}$ after the precursor deposition. The applied heat treatment consisted of a soft-bake at $160{ }^{\circ} \mathrm{C}$ for $30 \mathrm{~min}$ to evaporate the solvent and a subsequent calcination at $500{ }^{\circ} \mathrm{C}$ for $2 \mathrm{~h}$ in oxygen depleted atmosphere under flow of 0.45 1/min Ar with addition of $0.051 / \mathrm{min}_{2}$ gas to avoid oxidation of the films/substrate. Further, to determine the relation between the film thicknesses vs. dipping speed, Si-wafers were coated with varying dipping speed and subjected to the soft-bake without additional calcination.

\subsection{Characterization}

\subsubsection{Microstructural analysis}

The coated substrates have been investigated with a Helios Nanolab 600 dual beam Scanning Electron Microscope (SEM) with $\mathrm{Ga}^{+}$Focused Ion Beam (FIB) source and Pt deposition system. 
Before FIB cross sectioning, a double layer of CVD Pt was deposited to avoid beam-induced artifacts on the surface. Images on FIB cross sections have been taken under $52^{\circ}$ sample-tilt and no digital tilt correction was applied. To avoid artifacts from surface charging, SEM specimens have been sputter-coated with a conductive Au film of a few nm thickness prior to investigation.

\subsubsection{Adhesion testing}

The coating adhesion test was conducted according to ISO 2409:2007(E) "Paints and varnishes Cross-cut test"[39]. The test was carried out with 6 parallel scribes of $1 \mathrm{~mm}$ spacing, resulting in the formation of a "hatch pattern". The area with the "hatch pattern" was analyzed by optical microscopy as well as SEM, followed by cross-sectional investigation via (FIB)-SEM. As per standard requirement, the test was repeated three times at different locations.

\subsubsection{Chemical compositional analysis}

Fourier Transform Infrared Spectroscopy (FT-IR) was carried out on films deposited on silicon wafer. The HSQ film on the backside of the wafer was removed before curing to avoid artefacts. FT-IR spectra were recorded on a Thermo Scientific Nicolet iN 10 MX in transmittance mode, whereby the background was collected on a reference silicon wafer of similar type.

\subsubsection{Thickness measurements}

The film thickness was measured optically by Spectroscopic Ellipsometry on a VASE ellipsometer. Only films deposited on Si-wafers in soft-baked condition were investigated.

\subsubsection{Corrosion performance}

Electrochemical Impedance Spectroscopy (EIS) was implemented to assess the barrier-properties of the coating by using a Gamry Ref 600 potentiostat in $0.5 \mathrm{M}$ Na-acetate buffer solution at $\mathrm{pH}$ 
6. EIS measurements were carried out after an open circuit measurement of $3600 \mathrm{~s}$ in a solution volume of $15 \mathrm{ml}$ and on an area of $2.1 \mathrm{~cm}^{2}$. Potentials were determined with a Standard Calomel Electrode and the system was perturbed with a Pt wire auxiliary electrode. The experiment was repeated on three samples for consistency.

\section{Results and Discussion}

\subsection{Film thickness}

Figure 1 shows the film thickness on a polished Si-wafer substrate at different dipping speeds. The reported film thickness corresponds to the film thickness after solvent evaporation, i.e. the remaining solids of the HSQ solution before curing. Although not shown here, similar film thicknesses were achieved at higher dipping speeds when the HSQ solution was diluted to lower solid content. Furthermore, it was evident that the log of the film thickness linearly depends on $\log$ of the dipping speed, suggesting a relation similar to the power-law relation between film thickness and dipping rate as described by Brinker et al.[40] for dip coating of $\mathrm{SiO}_{2}$ sol-gel films. Since HSQ films undergo shrinkage during curing, the direct determination of the final film thickness from Figure 1 is not possible. Under the given curing conditions, HSQ films are expected to shrink by $10-15 \%$ of the initial thickness[29] and the values reported in Figure 1 have to be corrected for shrinkage when concluding on the final film thickness.

\subsection{Optical appearance}

The optical appearance of the test coupon after curing of the material is shown in Figure 2. The coating deposition led to the formation of a transparent surface film, which, depending on the film thickness, showed slight blue/violet discoloration from thin film interference. In general, the 
film was homogeneous and no island formation was observed. Although not presented here, there was no significant optical appearance difference in the coated area before and after curing.

\subsection{Surface morphology and cross-sectional analysis}

The detailed microstructure of the film was analyzed by SEM and FIB-SEM, as presented in Figure 3. Comparison between top view micrographs of a reference coupon (Figure 3a) and coated sample (Figure $3 b$ ) shows that the coating covers the surface and smoothens out the substrate grain boundary cavities from the 2B finish. Furthermore, there was no visible evidence of cracking or spallation of the coating at the top surface. The cross sectional analysis by FIBSEM (Figure 3c) confirmed that the coating was well adherent to the substrate and neither showed cavities under the coating nor exfoliation. Moreover, film formation in substrate voids, in particular in the $2 \mathrm{~B}$ grain-boundary trenches was observed, which resulted in the leveling of present undulations and roughness of the substrate. These results are in agreement with previous studies, where the leveling effect of HSQ surface treatments on metallic polymer molding tools[31-34] was investigated and reduction of peak to valley roughness up to a factor of 20 for mechanically ground aluminum surfaces was reported[34]. As visible from the micrograph, the simple thickness/dipping speed relation described in section 3.1 does not apply for coatings on rough substrates, where the thickness is determined by the inhomogeneous influence of substrate undulations, rather than the dipping speed. In this perspective, a precise value of film thickness could not be determined from Figure 3c. However, the minimum thickness of the film at the substrate surface was approximately $200 \mathrm{~nm}$ and on voids and undulations areas showed a maximum thickness of approximately $1000-1400 \mathrm{~nm}$. 


\subsection{Adhesion testing}

Figure 4 shows the results of the adhesion test. In general, no evidence of delamination (Figure 4a) was observed from the optical analysis and the coating was assessed as "0" according to standard test classification[39]. However, coating delamination in the close vicinity of the scribe was visible from SEM analysis, as shown in Figure 4b. To further investigate the nature of the delamination, the vicinity of the scribe was investigated by FIB-SEM cross-sectioning, as presented in Figure 4c. It was evident that the delaminated segment of the coating was completely removed from the surface during the test. Further, the coating delamination showed a mixed behavior by both adhesive and, to a minor extend, cohesive failure, as visible from the detail in Figure 4c.

\subsection{Chemical compositional analysis}

The chemical composition of soft-baked (uncured) and cured films were analyzed by FT-IR, which is a well-established characterization technique to gain semi-quantitative information about the cage to network transformation and Si-H loss in HSQ films[38,41]. The FT-IR absorption spectra of the HSQ films on Si-wafer before and after curing are shown in Figure 5. Non-polymerized HSQ is a cage-like oligomer with a siloxane backbone and $\mathrm{Si}-\mathrm{H}$ corner moieties[41], as indicated by $\mathrm{A}$ and $\mathrm{B}$ in Figure 6, respectively, and shows distinct FT-IR absorption bands from the Si-O asymmetric stretching of siloxane cages at $1140 \mathrm{~cm}^{-1}$ and $\mathrm{Si}-\mathrm{H}$ stretching from corner moieties at $2260 \mathrm{~cm}^{-1}$, as shown in Figure 5. During the heat treatment the cage oligomers polymerize via a multi-step redistribution reaction[25], forming networked siloxane bonds between cages, as indicated by notation "C" in Figure 6. In general, Si-O asymmetric stretching of networked siloxane shows an absorption peak shift in FT-IR, leading to 
the $\mathrm{Si}-\mathrm{O}$ asymmetric stretching edge at $1075 \mathrm{~cm}^{-1}$ as presented in Figure 5. Apart from $\mathrm{Si}-\mathrm{H}$ stretching at $2260 \mathrm{~cm}^{-1}$, another lower intensity absorption from Si-H stretching caused by $\mathrm{H}_{2} \mathrm{SiO}_{2 / 2}$ [42] was observed at $2200 \mathrm{~cm}^{-1}$, which is indicated by notation " $\mathrm{D}$ " in Figure 6 . The presence of $\mathrm{H}_{2} \mathrm{SiO}_{2 / 2}$ bands indicate the formation of an intermediate reaction product in the multi-step cage to network redistribution reaction, as described by Siew et al.[25], and are therefore indicative for an incomplete polymerization of the HSQ film. Overall, these results showed that the applied heat treatment cycle led to a partial transformation from HSQ to $\mathrm{SiO}_{\mathrm{x}}$, i.e. to the formation of a networked structure with a siloxane backbone and some remaining Si$\mathrm{H}$.

These findings are in well agreement with earlier studies[26,29], where curing at $500{ }^{\circ} \mathrm{C}$ led to an incomplete cage to network transformation, while temperatures of $650-800{ }^{\circ} \mathrm{C}$ fully transformed HSQ into a ceramic with virtually no remaining $\mathrm{Si}-\mathrm{H}$ and a stoichiometry close to $\mathrm{SiO}_{2}$. High remaining $\mathrm{Si}-\mathrm{H}$ ratios have shown to positively influence the film properties and the films reported in this study are expected to show low film stress as well as a high stability to moisture adsorption[38].

\subsection{Electrochemical Impedance Spectroscopy}

A widely used method to assess the barrier properties of inert thin film ceramic coatings is Electrochemical Impedance Spectroscopy (EIS)[8,9,13,43-45]. A Bode plot of the measured impedance spectra of an uncoated AISI $316 \mathrm{~L}$ reference coupon and a coated test coupon is shown in Figure 7. The reference sample shows one capacitive maximum, indicating a simple charge transfer reaction over a double layer, while the spectrum acquired for the coated sample 
can be separated into two distinct capacitive maxima, indicating a charge transfer mechanism over the film that involves two capacitances of different origin as well as ohmic transport.

The quantitative interpretation of EIS data requires fitting with a correct equivalent circuit model. Thus, the interpretation of a charge transfer over a double layer, as it was observed for a bare electrode immersed into an electrolyte, can be described by a Randle's equivalent circuit as shown in Figure 8a[46]. In contrast, various equivalent circuits have been proposed for steel substrates covered with $\mathrm{SiO}_{2}$ thin films[8,9,44,45]. Pech et al.[9] discussed pore and pinhole free $\mathrm{SiO}_{2}$ coatings as blocking electrodes, which can be modelled as a solution resistance in series with a capacitive element. However, their model is only applicable for systems showing a single capacitive plateau and therefore is not applicable to systems, which indicate ohmic charge transport over the coating. Others[8,44,45] observed impedance responses with two capacitive maxima and applied different equivalent circuits to analyze their data. Walke et al.[44,45] analyzed sol-gel $\mathrm{SiO}_{2}$ on stainless steel substrate with a $\mathrm{R}-(\mathrm{QR})-(\mathrm{QR})$-type model, whereas, Pech et al.[8] applied a R-(Q(R-(QR))) -type model to conclude on the impedance response of PACVD $\mathrm{SiO}_{2}$ coatings on $\mathrm{M} 2$ high speed steel.

In the present study, the reordered impedance data of the coated specimen was fitted with both equivalent circuits, as presented in Figure 7. Residuals plots for the fits are shown in Figure 9. These fitted data plots showed that R-(QR)-(QR) gave inadequate fit results, showing large, systematic deviations from the measured data, whereby $\mathrm{R}-(\mathrm{Q}(\mathrm{R}-(\mathrm{QR})))$ showed good results in the high frequency region ( $\mathrm{f}>10 \mathrm{~Hz}$ ), however, deviated from the experimental data in the low frequency region $(\mathrm{f}<10 \mathrm{~Hz}$ ). In this case, the addition of a semi-infinite diffusional impedance (semi-infinite Warburg impedance) could improve the fitting, yielding a $\mathrm{R}-(\mathrm{Q}(\mathrm{R}-(\mathrm{Q}(\mathrm{WR})))$ ) type circuit, as presented in Figure 7 and Figure 9, which was in agreement with reported 
literature[43]. A graphic representation of the equivalent circuit for the coated system is shown in Figure 8b.

The proper circuit fit of the data from Figure 7 with the equivalent circuits shown in Figure 8 , using the relation described by Hsu et al.[47] for the conversion between constant phase element and equivalent capacitance, yielded the results displayed in Table 1. Overall, the coated specimen showed high barrier efficiency by exhibiting a pore resistance $R_{p}$ of $907 \mathrm{k} \Omega \mathrm{cm}^{2}$ as well as an increase in total modulus IZI of the test coupons from $983 \mathrm{k} \Omega \mathrm{cm}^{2}$ for the reference to 214 $\mathrm{M} \Omega \mathrm{cm}^{2}$. Moreover, the coated test coupon showed a decrease in equivalent double layer capacitance $\mathrm{C}_{\mathrm{eq}, \mathrm{dl}}$ by three orders of magnitude, which indicates a significant decrease in electrolyte-exposed surface[8], i.e. a high degree of coating coverage.

Overall, the coating showed characteristics similar to silica coatings obtained by other methods such as CVD[8] or sol-gel[13], namely a highly a high resistance to ionic transport through coating defects combined with a high degree of coating coverage. However, since the previous studies were based on an assessment of the coating performance in $\mathrm{NaCl}$ solution, a quantitative assessment of the performance of the HSQ-based coating in respect to other coating systems is not possible solely based on this study. Further investigations have to be conducted to conclude on the barrier efficiency of the coating in technically relevant media such as chloride solutions, which are well known to induce localized failure in stainless steels[1].

\section{Conclusions}

1. HSQ-based thin film coatings can be applied to stainless steels by dip coating to form crack free thin film enamels. Further, the deposited coatings showed good leveling abilities, adhesion and did not show any interfacial cracking or spallation. 
2. The thickness of the deposited film on a rough substrate was approx. $200-400 \mathrm{~nm}$, which could not be estimated by interpolation of data collected on smooth substrates.

3. Film curing at $500{ }^{\circ} \mathrm{C}$ led to a significant polymerization of the HSQ precursor, yielding cross-linked films with a siloxane backbone and some remaining Si-H.

4. The electrochemical impedance response of the coating system could be modelled by an $\mathrm{R}-(\mathrm{Q}(\mathrm{R}-(\mathrm{Q}(\mathrm{WR}))))$-type model, which accounts for ionic transport over the coating and compensates for diffusion in the test setup.

5. The coating indicated high barrier properties and a high substrate coverage, by exhibiting a pore resistance of $907 \mathrm{k} \Omega \mathrm{cm}^{2}$ and a decrease in double layer capacitance by 3 orders of magnitude.

\section{Acknowledgements}

The authors acknowledge SiOx Aps for the deposition of coatings and all other project partners. Further, Innovation Fund Denmark is acknowledged for providing financial support for the project Q-HEX [grant number 50-2014-1].

\section{References}

[1] E. Bardal, Corrosion and Protection, Springer-Verlag London Ltd., London, 2004.

[2] E. Deltomee, N. de Zoubov, M. Pourbaix, 10.1 Chromium, in: Atlas Electrochem. Equilibria Aqueous Solut., NACE, Houston, 1996: pp. 256-271. 
[3] K.M. Deen, M. a. Virk, C.I. Haque, R. Ahmad, I.H. Khan, Failure investigation of heat exchanger plates due to pitting corrosion, Eng. Fail. Anal. 17 (2010) 886-893.

[4] Z. Szklarska-Smialowska, J. Mankowski, Crevice Corrosion of Stainless Steels in Sodium Chloride Solution, Corros. Sci. 18 (1978) 953-960.

[5] H.C. Wilson, Acid Resisting Properties of Porcelain Enamels, Symp. Porc. Enamels Ceram. Coatings as Eng. Mater. 1954 (1954) 26-28.

[6] P. Møller, L.P. Nielsen, Vitreous Enamel, in: Adv. Surf. Technol. Vol 2, 2013: pp. 645654.

[7] H. Laithwaite, Some Properties of Vitreous Enamels and their practical Significance, Sheet Met. Ind. 31 (1954) 775-780.

[8] D. Pech, P. Steyer, A.-S. Loir, J.C. Sánchez-López, J.-P. Millet, Analysis of the corrosion protective ability of PACVD silica-based coatings deposited on steel, Surf. Coatings Technol. 201 (2006) 347-352.

[9] D. Pech, P. Steyer, J.-P. Millet, Electrochemical behaviour enhancement of stainless steels by a SiO2 PACVD coating, Corros. Sci. 50 (2008) 1492-1497.

[10] D.C.L. Vasconcelos, J.A.N. Carvalho, M. Mantel, W.L. Vasconcelos, Corrosion resistance of stainless steel coated with sol-gel silica, J. Non. Cryst. Solids. 273 (2000) 135-139.

[11] O. de Sanctis, L. Gomez, N. Pellegri, C. Parodi, A. Marajofsky, A. Duran, Protective Glass Coatings on Metallic Substrates, J. Non. Cryst. Solids. 121 (1990) 338-343. 
[12] O. de Sanctis, L. Gomez, N. Pellegri, A. Duran, Behaviour in hot ammonia atmosphere of $\mathrm{SiO} 2$-coated stainless steels produced by a sol-gel procedure, Surf. Coatings Technol. 70 (1995) 251-255.

[13] B. Nikrooz, M. Zandrahimi, H. Ebrahimifar, High temperature oxidation resistance and corrosion properties of dip coated silica coating by sol gel method on stainless steel, J. Sol-Gel Sci. Technol. 63 (2012) 286-293.

[14] K. Baba, R. Hatada, S. Nagata, H. Fujiyama, G.K. Wolf, W. Einsinger, SiO2 coatings produced by ion beam assisted ECR-plasma CVD, Surf. Coatings Technol. 75 (1995) 292-296.

[15] G.A. Garzino-Demo, F.L. Lama, Friction and wear of uncoated or SiO2-coated 329 stainless steel and of uncoated or A1N-coated aluminium surfaces, Surf. Coatings Technol. 68/69 (1994) 507-511.

[16] W. Hänni, H.E. Hintermann, D. Morel, A. Simmen, Silica Coatings on Strongly Passivated Substrates, Surf. Coatings Technol. 36 (1988) 463-470.

[17] S. Benayoun, L. Fouilland-Paille, J.J. Hantzpergue, Microscratch test studies of thin silica films on stainless steel substrates, Thin Solid Films. 352 (1999) 156-166.

[18] A. Delimi, Y. Coffinier, B. Talhi, R. Boukherroub, S. Szunerits, Investigation of the corrosion protection of SiOx-like oxide films deposited by plasma-enhanced chemical vapor deposition onto carbon steel, Electrochim. Acta. 55 (2010) 8921-8927. 
[19] S. Nitta, Y. Kimura, Formation of SiO2 Thin Film on SUS304 Stainless Steel by Liquid Phase Deposition (in Japanese), J. Soc. Matierals Sci. Japan. 43 (1994) 1437-1443.

[20] J. de Damborenea, N. Pellegri, O. Sanctis, A. Duran, Electrochemical Behaviour of SiO2 Sol-Gel Coatings on Stainless Steel, J. Sol-Gel Sci. Technol. 4 (1995) 239-244.

[21] C.J. Brinker, G.W. Scherer, Hyrdolysis and Condensation of Silicon Alkoxides, in: SolGel Sci., Academic Press, Inc., San Diego, 1990: pp. 108-216.

[22] C.J. Brinker, G.W. Scherer, Sintering, in: Sol-Gel Sci., Academic Press, Inc., San Diego, 1990: pp. 675-742.

[23] M. Takemori, Crack formation, exfoliation, and ridge formation in $500{ }^{\circ} \mathrm{C}$ annealed solgel silica coatings on stainless steel SUS304: Part I. Microscopic observations and elemental analysis, Ceram. Int. 35 (2009) 1731-1746.

[24] M. Takemori, Crack formation, exfoliation, and ridge formation in $500{ }^{\circ} \mathrm{C}$ annealed solgel silica coatings on stainless steel SUS304: Part II Spectroscopic and mechanical analyses and insights into mechanisms controlling coating characteristics, Ceram. Int. 35 (2009) 1747-1755.

[25] Y.K. Siew, G. Sarkar, X. Hu, J. Hui, A. See, C.T. Chua, Thermal Curing of Hydrogen Silsesquioxane, J. Electrochem. Soc. 147 (2000) 335.

[26] H. Liou, J. Pretzer, Effect of curing temperature on the mechanical properties of hydrogen silsesquioxane thin films, Thin Solid Films. 335 (1998) 186-191. 
[27] W.-C. Liu, C.-C. Yang, W.-C. Chen, B.-T. Dai, M.-S. Tsai, The structural transformation and properties of spin-on poly(silsesquioxane) films by thermal curing, J. Non. Cryst. Solids. 311 (2002) 233-240.

[28] V. Belot, R.J.P. Corriu, D. Leclercq, P.H. Mutin, A. Vioux, Redistribution reactions in silsesquioxane gels, J. Mater. Sci. Lett. 9 (1990) 1052-1054.

[29] D. Tobben, P. Weigand, M.J. Shapiro, S.A. Cohen, Influence of the cure process on the properties of hydrogen silsesquioxane spin-on-glass, Mater. Res. Soc. Somposium Proc. 443 (1997) 195-200.

[30] P. Kohl, Low-dielectric constant insulators for future integrated circuits and packages, Annu. Rev. Chem. Biomol. Eng. 2 (2011) 379-401.

[31] K. Mohaghegh, H.N. Hansen, H. Pranov, G. Kofod, A study on the surface roughness of a thin HSQ coating on a fine milled surface, in: 14th Euspen Int. Conf. - Dubrovink, 2014.

[32] K. Mohaghegh, H.N. Hansen, H. Pranov, G. Kofod, Verification of thickness and surface roughness of a thin film transparent coating, in: Proc. 13th Euspen Int. Conf., Berlin, 2013.

[33] H. Pranov, Spin-on-glass assisted polishing of rough substrates, WO 2103/083129 A1, 2013. 
[34] J. Cech, H. Pranov, G. Kofod, M. Matschuk, S. Murthy, R. Taboryski, Surface roughness reduction using spray-coated hydrogen silsesquioxane reflow, Appl. Surf. Sci. 280 (2013) $424-430$.

[35] T.C. Hobæk, M. Matschuk, J. Kafka, H.J. Pranov, N.B. Larsen, Hydrogen silsesquioxane mold coatings for improved replication of nanopatterns by injection molding, J. Micromechanics Microengineering. 25 (2015) 035018.

[36] H. Pranov, Reactive Silicon Oxide Precursor Facilitated Anti-Corrosion Treatment, US 2014/0154441 A1, 2014.

[37] F. Lampert, A.H. Jensen, P. Møller, Low Temperature Curing of Hydrogen Silsesquioxane Surface Coatings for Corrosion Protection of Aluminum, NASF Surf. Technol. White Pap. 80 (2016) 1-8.

[38] J.N. Bremmer, Y. Liu, K.G. Gruszynski, F.C. Dall, Cure of Hydrogen Silsesquioxane for Intermetal Dielectric Applications, Mater. Res. Soc. Somposium Proc. 476 (1997) 37-44.

[39] ISO 2409:2007(E) Paints and varnishes - Cross-cut test, (2007).

[40] C.J. Brinker, G.W. Scherer, Physics of Film Formation, in: Sol-Gel Sci., 1990: pp. 788797.

[41] C.L. Frye, W.T. Collins, The Oligomeric Silsesquioxanes, (HSiO3/2)n, J. Am. Chem. Soc. 92 (1970) 5586-5588. 
[42] M.G. Albrecht, C. Blanchette, Materials Issues with Thin Film Hydrogen Silsesquioxane Low K Dielectrics, J. Electrochem. Soc. 145 (1998) 4019-4025.

[43] C. Liu, Q. Bi, A. Leyland, A. Matthews, An electrochemical impedance spectroscopy study of the corrosion behaviour of PVD coated steels in $0.5 \mathrm{~N} \mathrm{NaCl}$ aqueous solution: Part I. Establishment of equivalent circuits for EIS data modelling, Corros. Sci. 45 (2003) $1243-1256$.

[44] W. Walke, Z. Paszenda, T. Pustelny, Z. Opilski, S. Drewniak, M. Ko, M. Basiaga, Evaluation of physicochemical properties of $\mathrm{SiO} 2$-coated stainless steel after sterilization, Mater. Sci. Eng. C. 63 (2016) 155-163.

[45] W. Walke, Z. Paszenda, M. Basiaga, P. Karasinski, M. Kaczmarek, EIS Study of SiO2 Oxide Film on 316L Stainless Steel for Cardiac Implants, in: E. Piętka, J. Kawa, W. Wieclawek (Eds.), Inf. Technol. Biomed. Vol 4., Springer International Publishing, Cham, 2014: pp. 403-410.

[46] F. Mansfeld, H. Shih, H. Greene, C.H. Tsai, Analysis of EIS Data for Common Corrosion Processes, in: Electrochem. Impedance Anal. Interpret., 1993: pp. 37-53.

[47] C.H. Hsu, F. Mansfeld, Technical Note: Concerning the Conversion of the Constant Phase Element Parameter Y0 into a Capacitance, Corrosion. 57 (2001) 747-748. 


\section{List of Figure Captions}

Figure 1: Film thickness vs. dipping speed after solvent evaporation (on polished Si-wafer).

Figure 2: Digital photograph of test coupon after curing.

Figure 3: SEM images of (a) uncoated reference (top view); (b) coated specimen (top view); (c) FIB-SEM cross section of coated sample. Au and Pt depositions are artifacts from the specimen preparation.

Figure 4: Cross-cut test of coating: (a) Optical micrograph of coating surface after the test; (b) SEM micrograph of scribe junction. The marker in the micrograph indicates the location of the FIB-SEM cut shown in Figure 4c; (c) FIB-SEM cross section across delaminated coating, where $\mathrm{Au}$ and $\mathrm{Pt}$ depositions are artifacts from the specimen preparation.

Figure 5: FT-IR absorption spectra of films deposited on Si-wafer.

Figure 6: Redistribution reaction of HSQ cage oligomers to a more networked structure (based on the redistribution reaction by Siew et al.[25]). 1 and 2 indicate atoms which are exchanged between the two neighboring cage oligomers.

Figure 7: Bode plots of coated and uncoated AISI $316 \mathrm{~L}$ in Na-acetate buffer solution.

Figure 8: Equivalent circuit models for: (a) reference; (b) coated sample. With solution resistance $R_{s}$, charge transfer resistance $R_{c t}$, pore resistance $R_{p}, C P E$ of double layer $Q_{d l}, C P E$ of coating $\mathrm{Q}_{\text {coat, }}$ reference electrode RE and working electrode WE.

Figure 9: Residuals of impedance fits shown in Figure 7. 


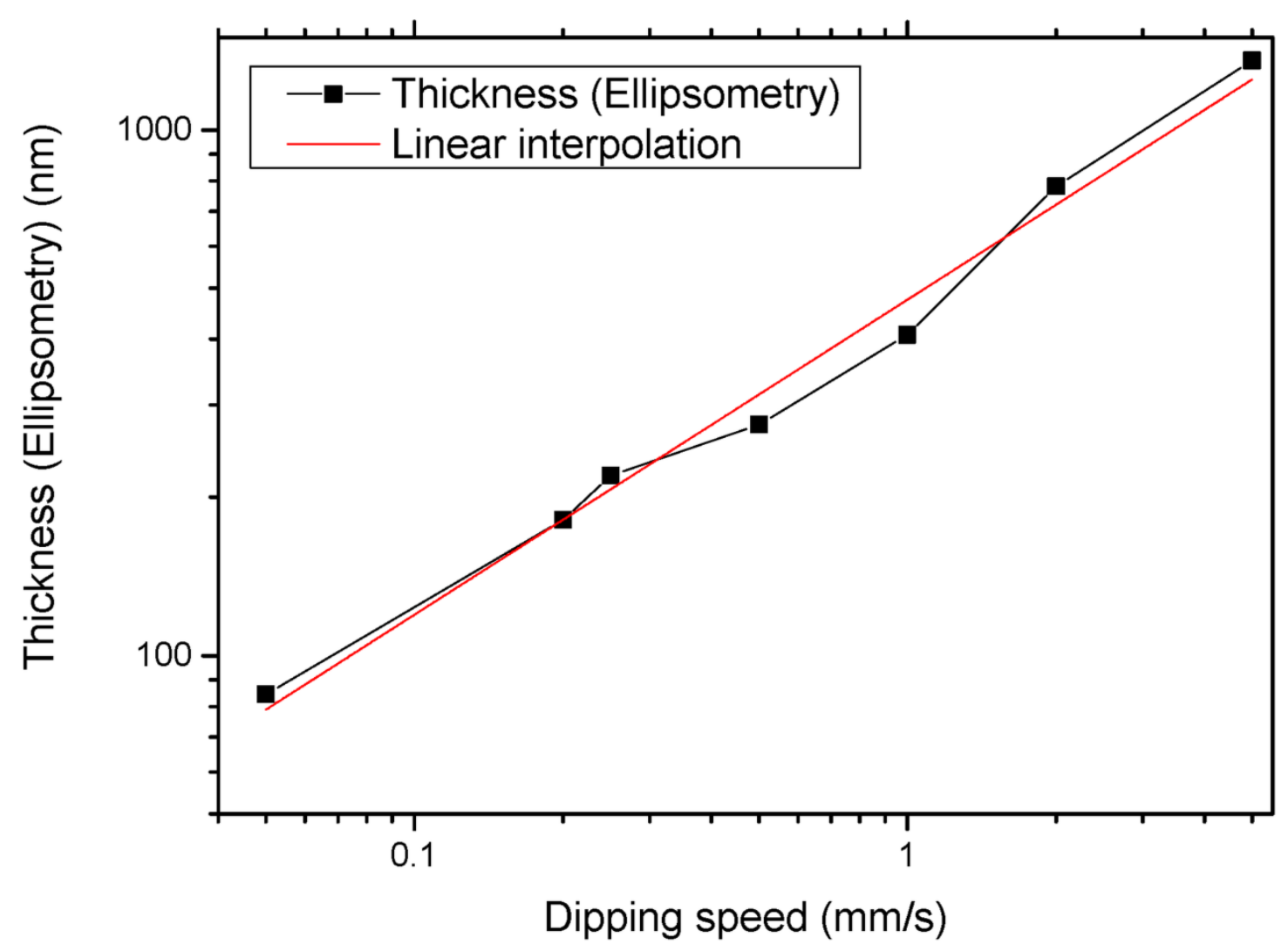

Figure 1 


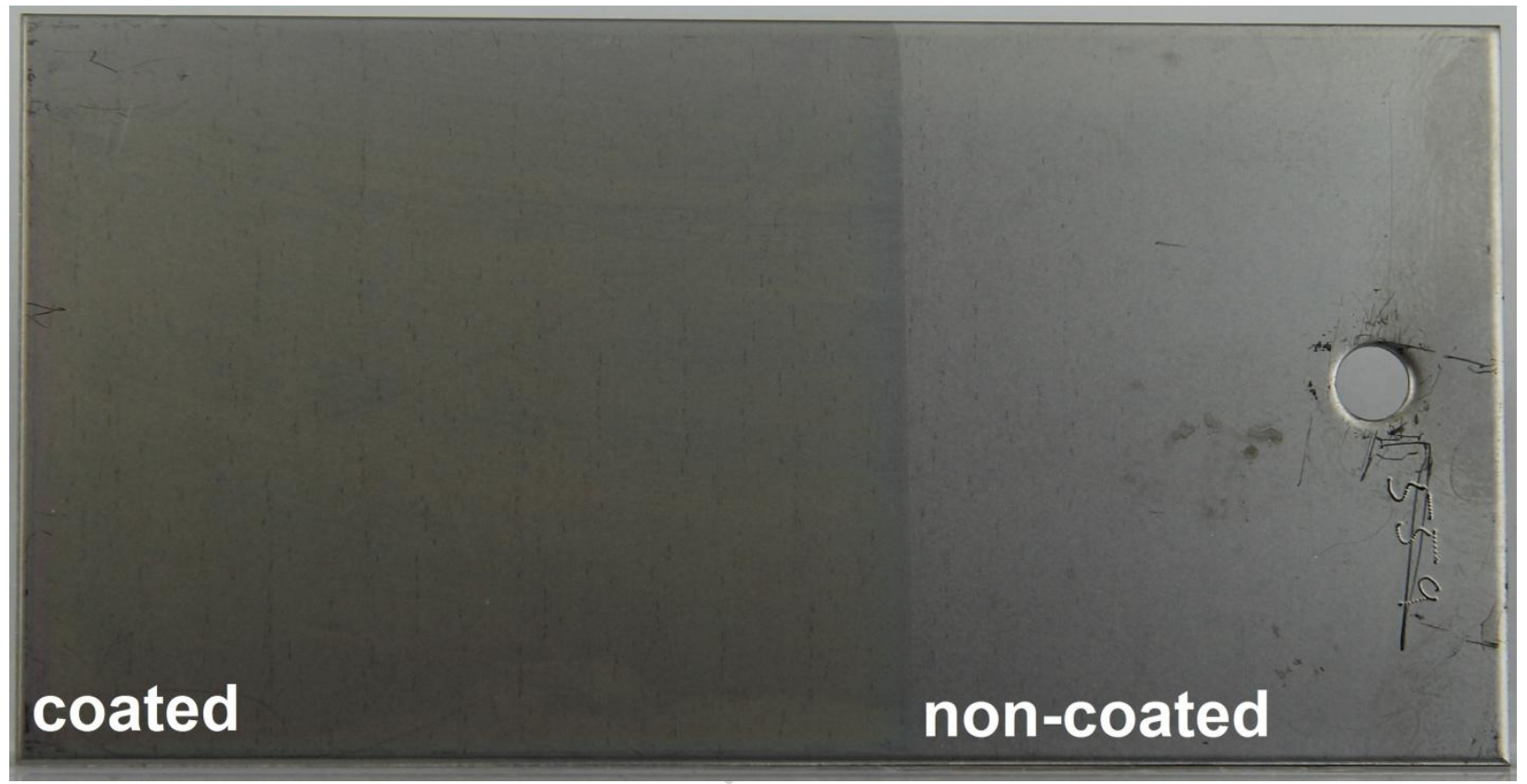

Figure 2 

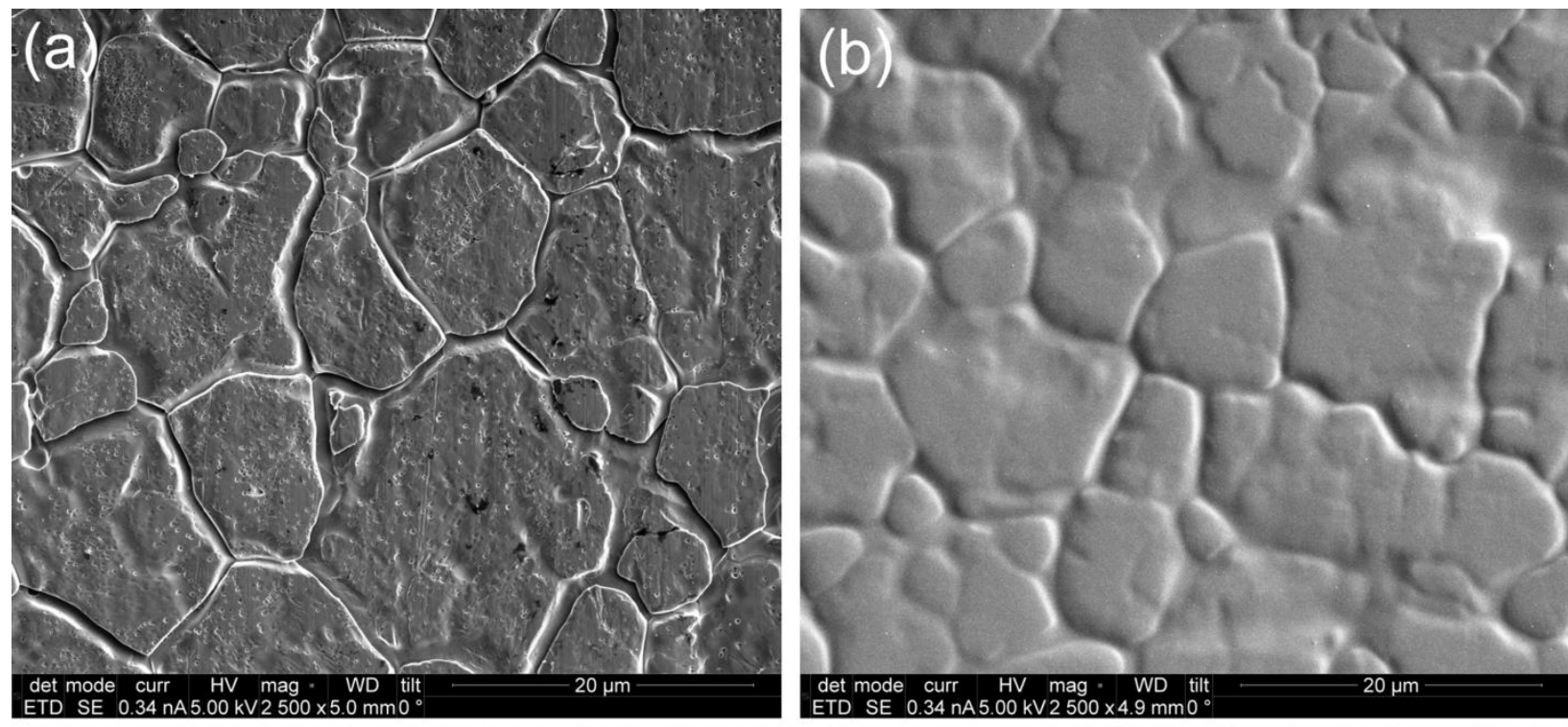

\section{(c)}

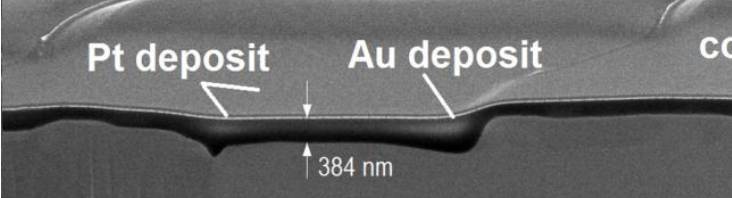

coating

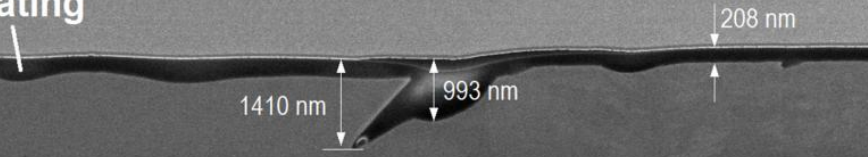

AISI 316 L substrate

Figure 3 

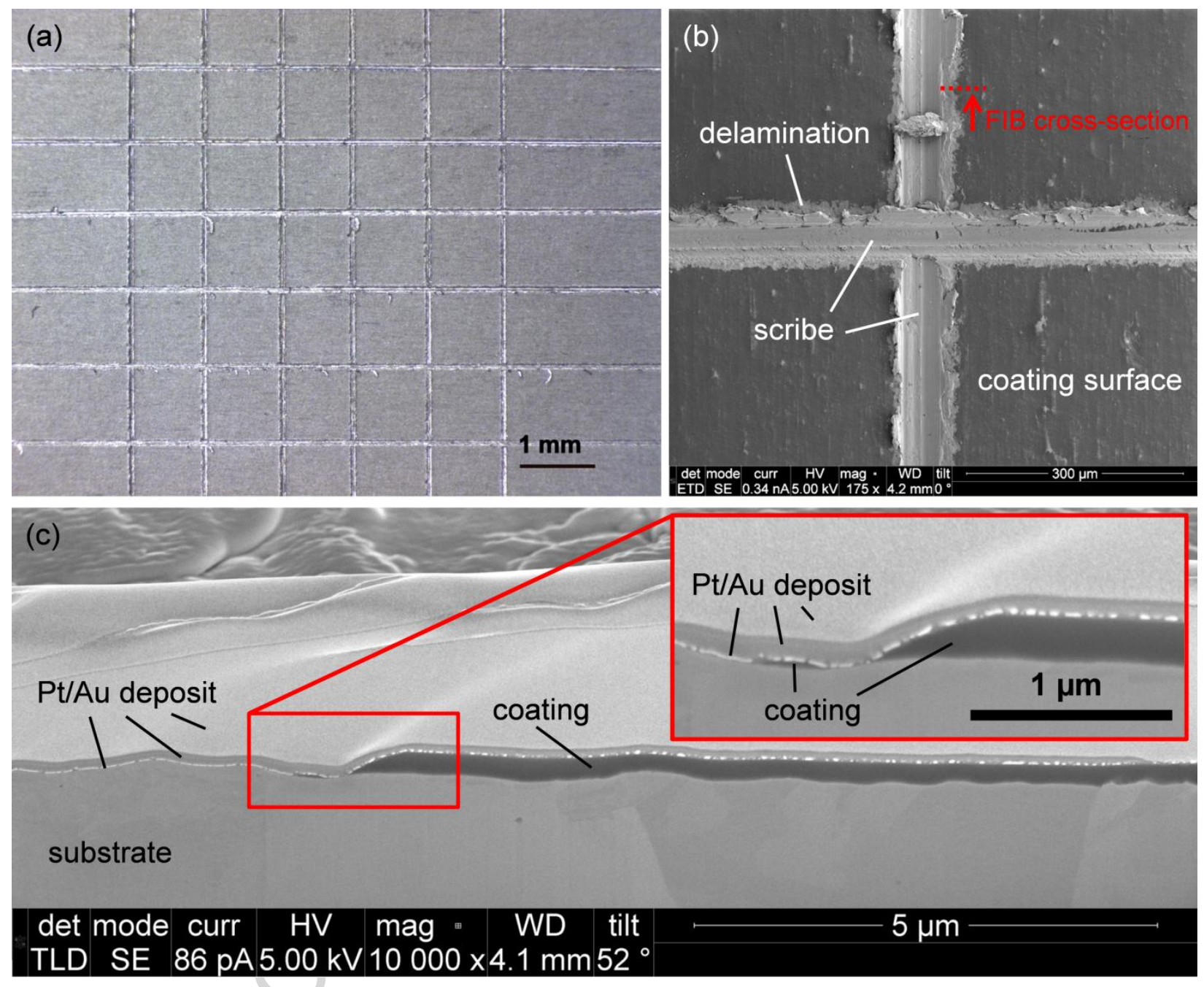

Figure 4 


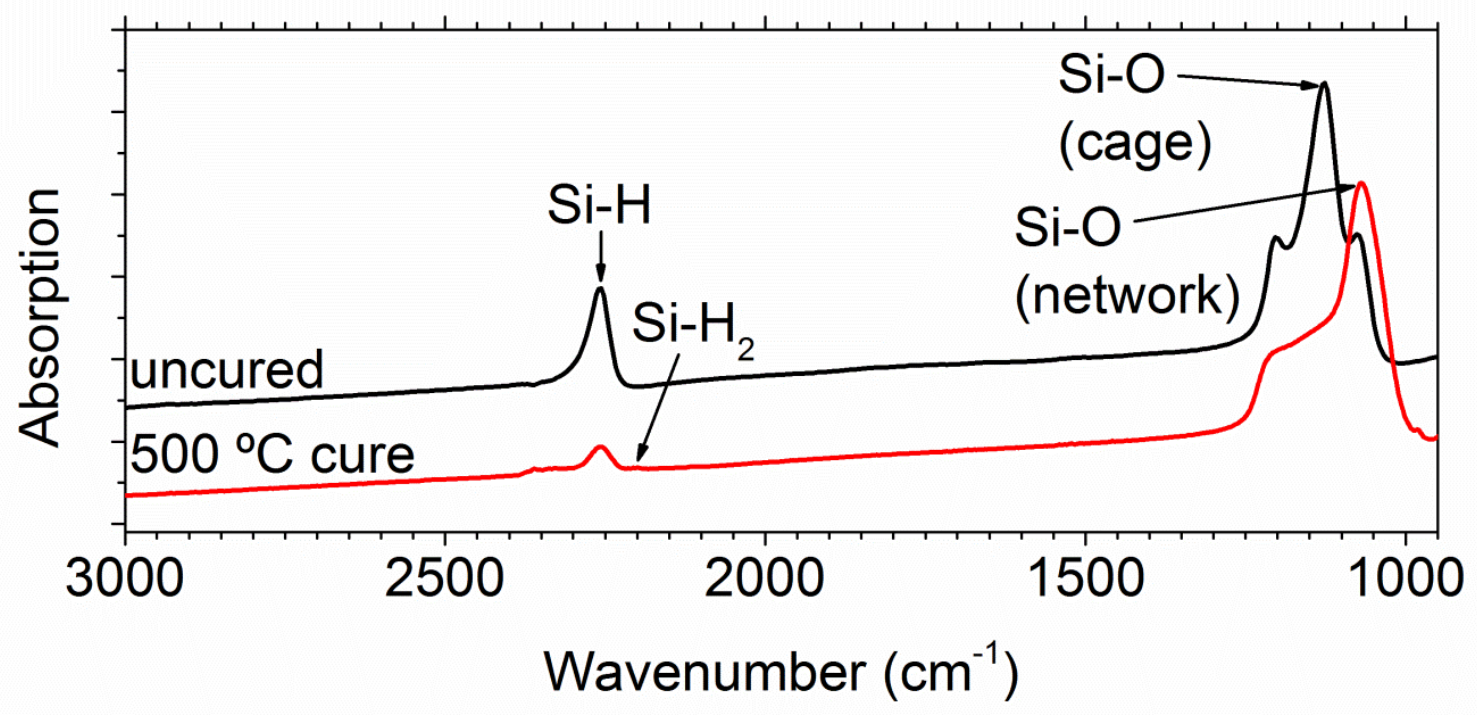

Figure 5 


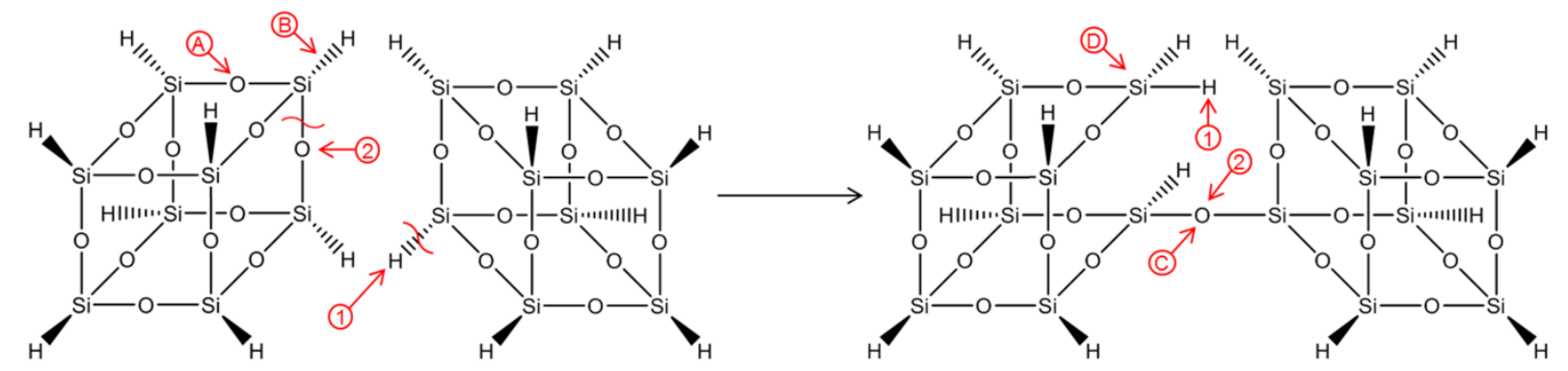

Figure 6 

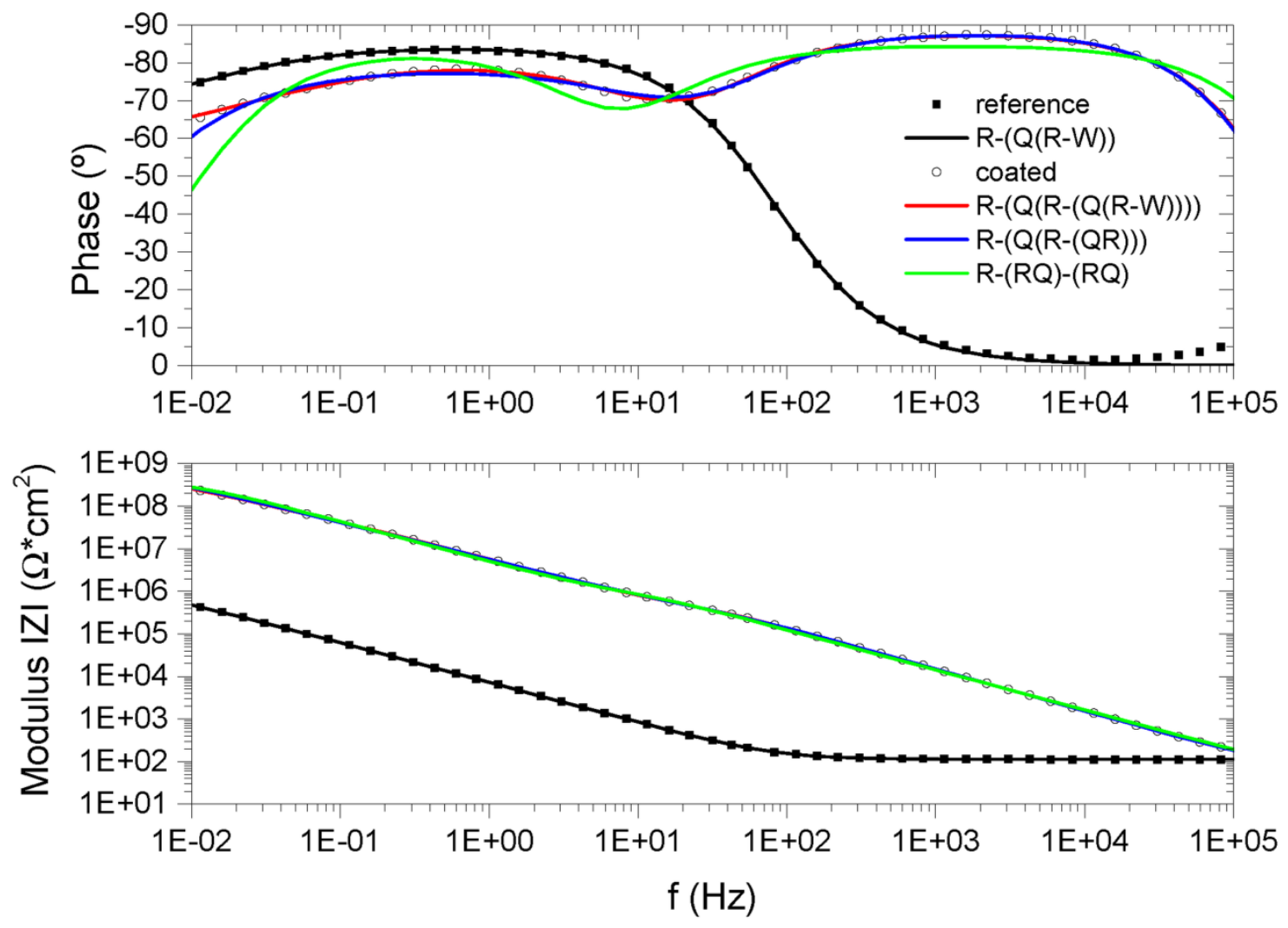

Figure 7 


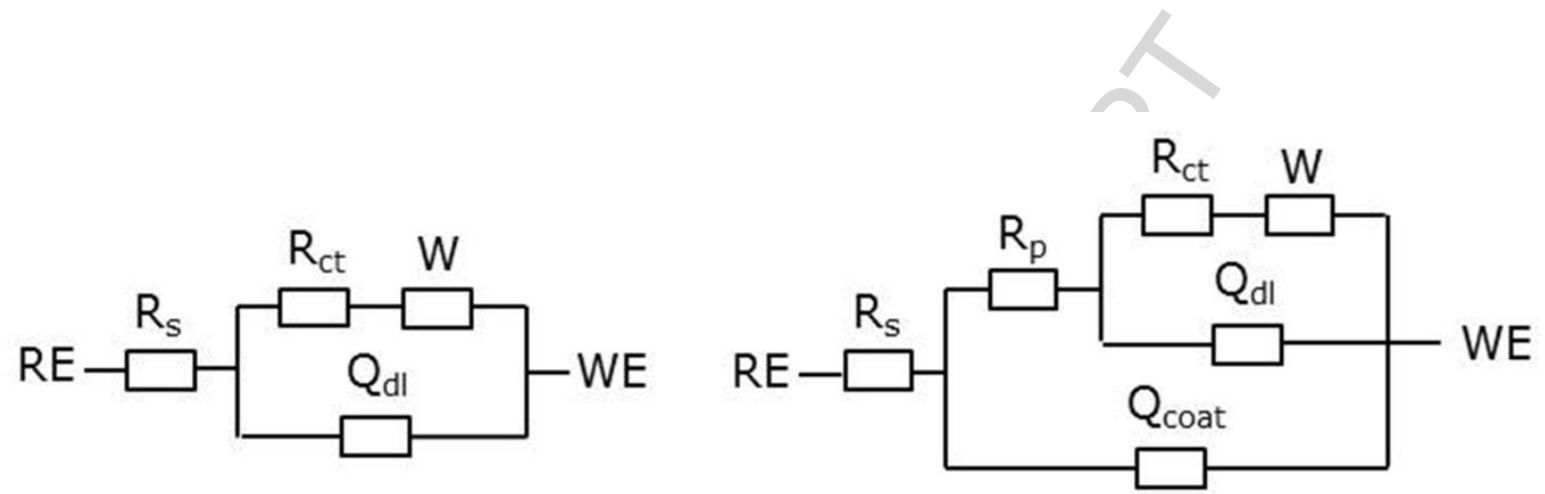

(a)

(b)

Figure 8 


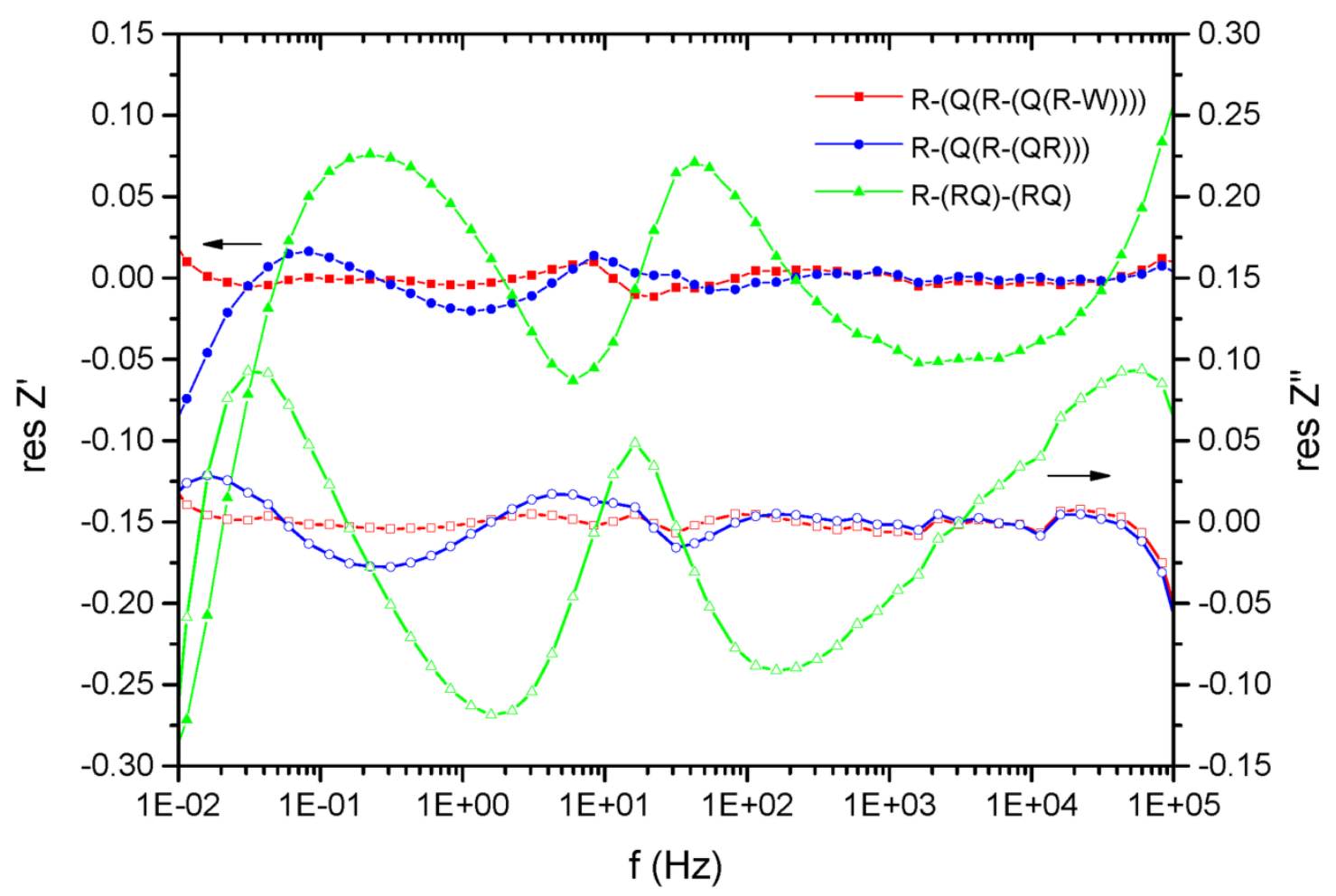

Figure 9 

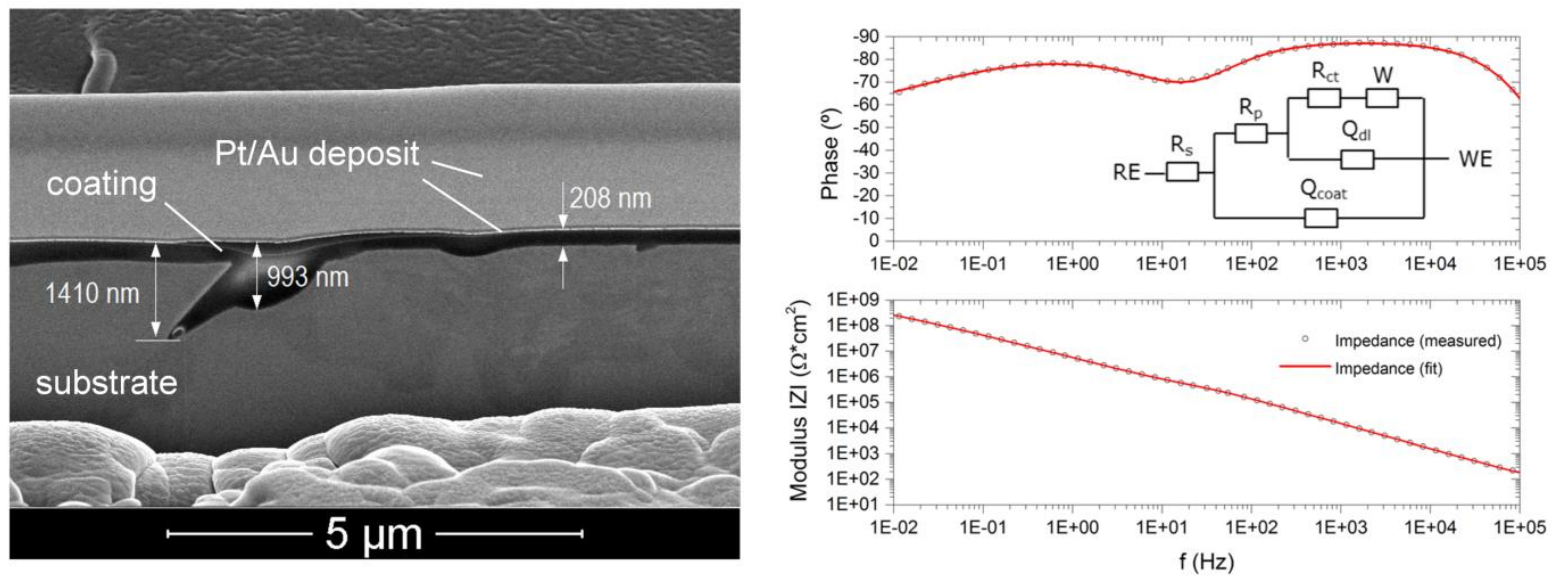

Graphical abstract 
Table 1 - Fitting results from EIS measurements.

\begin{tabular}{|c|c|c|c|c|c|c|c|c|}
\hline Sample & $\begin{array}{l}\operatorname{Rp} \\
\left(\Omega * \mathrm{~cm}^{2}\right)\end{array}$ & $\begin{array}{l}Q_{0, \text { coat }} \\
\left(\mathrm{Ss}^{\alpha} / \mathrm{cm}^{2}\right)\end{array}$ & $\boldsymbol{\alpha}_{\text {coat }}$ & $\begin{array}{l}\mathrm{C}_{\text {eq,coat }} \\
\left(\mathrm{F} / \mathrm{cm}^{2}\right)\end{array}$ & $\begin{array}{l}\mathbf{R}_{\mathrm{ct}} \\
\left(\Omega^{*} \mathrm{~cm}^{2}\right)\end{array}$ & $\begin{array}{l}\mathrm{Q}_{0, \mathrm{dl}} \\
\left(\mathrm{Ss}^{\alpha} / \mathrm{cm}^{2}\right)\end{array}$ & $\alpha_{\mathrm{dl}}$ & $\begin{array}{l}\mathrm{C}_{\mathrm{eq}, \mathrm{dl}} \\
\left(\mathrm{F} / \mathrm{cm}^{2}\right)\end{array}$ \\
\hline reference & - & - & - & - & $9.83 E+05$ & $2.45 \mathrm{E}-05$ & 0.941 & $3.00 \mathrm{E}-05$ \\
\hline coated & $9.07 \mathrm{E}+05$ & $1.28 \mathrm{E}-08$ & 0.98 & $1.17 \mathrm{E}-08$ & $2.13 \mathrm{E}+08$ & $2.11 \mathrm{E}-08$ & 0.856 & $2.72 \mathrm{E}-08$ \\
\hline
\end{tabular}




\section{Highlights}

- The deposition of thin film $\mathrm{SiO}_{2}$ coatings from HSQ precursor on stainless steel is demonstrated

- The coating good coverage and smoothens out substrate roughness and defects

- An impedance model is proposed to assess the barrier properties in aqueous solutions

- The coating shows good barrier properties

- Electrolyte contact with the substrate is established via microscopic coating defects 